\title{
Using Mathematics Lessons in Adolescents' Sex Education
}

\section{Jaime Cofre ${ }^{*}$, Lúcio S. Macedo², Rodolfo C. Braga², Allef V. P. G. de Moreira², Gustavo R. de Souza ${ }^{2}$, Viviane M. Rodrigues ${ }^{3}$, Ricardo Nascimento ${ }^{4}$, Maria Salete M. Vieira ${ }^{4}$, Evaldo dos Santos ${ }^{4}$}

\author{
${ }^{1}$ Sexual and Reproductive Health Program, Universidade Federal de Santa Catarina, Florianópolis, Brazil \\ ${ }^{2}$ Faculty of Medicine, Universidade Federal de Santa Catarina, Florianópolis, Brazil \\ ${ }^{3}$ Secretaria Municipal de Educação, Florianópolis, Brazil \\ ${ }^{4}$ Department of Obstetrics \& Gynecology, Universidade Federal de Santa Catarina, Florianópolis, Brazil \\ Email: *jaime.cofre@ufsc.br
}

How to cite this paper: Cofre, J., Macedo, L.S., Braga, R.C., de Moreira, A.V.P.G., de Souza, G.R., Rodrigues, V.M., Nascimento, R., Vieira, M.S.M. and dos Santos, E. (2018) Using Mathematics Lessons in Adolescents' Sex Education. Open Journal of Social Sciences, 6, 204-230.

https://doi.org/10.4236/jss.2018.67016

Received: June 6, 2018

Accepted: July 28, 2018

Published: July 31, 2018

Copyright (C) 2018 by authors and Scientific Research Publishing Inc. This work is licensed under the Creative Commons Attribution International License (CC BY 4.0).

http://creativecommons.org/licenses/by/4.0/

\begin{abstract}
The present article shows the connection between sex education workshops and mathematics teaching, and how schoolchildren can learn from this discipline more healthy and caring behaviors regarding their sexual life. The schoolchildren who have received sex education in the math context recall more about sexually transmitted diseases (STDs) and claim to be better acquainted with prevention methods. A significant advance of our sexual and reproductive health program is the sharp decrease of $15 \%(\mathrm{p}<0.025)$ among adolescents who never use condoms. Thus, the teaching of mathematics adequately oriented to sex education may contribute (along with other school disciplines) to greater protection of adolescents, in the southern region of Brazil. Also, it is possible to confirm that creative educational strategies can make a big difference in the prevention of adolescents and young people contamination with STDs, in Brazil and worldwide.
\end{abstract}

\section{Keywords}

Sexual Education, School-Based Sex Education, Education of Adolescents, Mathematic Lessons, STDs Prevention

\section{Introduction}

It is possible to observe through the AIDS Epidemiological Bulletin of 2016 (published in 2017) [1] that Florianópolis/SC (the second most important place among the capitals and $97^{\text {th }}$ among the Brazilian municipalities) shows AIDS incidence rates of 53.7/100.000 inhabitants. On the other hand, the south of the 
country stood out, in 2015, with the highest detection rate of 12.6/100.000 inhabitants in the age group between 13 - 24 years. Thus, it was essential to elaborate strategies and actions integrated by formal institutions of society that allow reducing the Brazilian adolescents and young people's vulnerability in that region.

Some studies of the World Health Organization showed that $22 \%$ of teenagers initiate the sexual activity at the age of 15 [2]. Also the National Research of the Student's Health showed that $27.5 \%$ of them, in the ninth grade, already had sexual intercourse [3] [4]. Our research data corroborates the anticipation of sexual life for the 11 - 12-year-old schoolchildren, in Florianopolis [5]. The primary concern with such information is that early sexual initiation is associated with the non-use or inappropriate use of condoms and its consequences [2] [3] [6].

The critical and symptomatic situation of adolescents' earlier sexual life associated with greater contamination of adolescents and young people with AIDS, in the southern region of Brazil, calls for a broad discussion of what is being done and what should have been done about it [7] and that it will be developed in another article. The point is that sex education is always drifting, and it is strongly influenced by changes in government policies and public opinion [8] [9]. Therefore, it is worrisome that twenty years ago, in 1998, the sex education was officially included, in the Brazilian national school curriculum [10] (the so-called National Curriculum Parameters) as a cross-cutting theme that should be linked to the contents of each school subject, in the primary (from the sixth grade) and high schools.

It is possible to observe in practice/reality that few efforts have been made to address issues of health and sexual education, in the school curriculum [8]. Initiatives addressing theoretical and methodological issues have been developed to assist teachers in dealing with various themes in sex education within the sphere of biological science and this approach is still deeply rooted. Unfortunately, the biomedical/biological discourse is the most valued and widespread in the schools in general [11] [12] [13] [14]. It is worth recognizing that the biomedical topics are favorable for discussion in science classes and constitute an important dimension to be addressed in sex education. For example, through the discussion on human reproduction in the subject of biological sciences, the children get information or concepts related to the anatomy and physiology of the human body. However, there is a well-established consensus in the literature pointing out that such approach does not usually cover the anxieties and curiosities of the children as it only focuses on the biological body, and it does not include the cultural, social and affective dimensions contained in the same body [13] [15]. A broad concept of sexual education and sexuality should cover all subjects within the school curriculum especially in a context like that of Florianopolis, where the incidence of HIV and STDs infection are matters of concern [1] [3].

In the Brazilian reality and particularly in the state of Santa Catarina, it is worth highlighting the inspirational work of the researcher Jimena Furlani who establishes the need for sex education at all levels of schooling, and it should be 
deeply rooted in school education [16] [17]. Some changes of course in the Latin American context are seen in the sexuality approach in the physical education classes [18]. According to the present work author, it is a coherent initiative with a view of sexuality as a cross-cutting theme that should be addressed by different ways, in many compulsory subjects of the school curriculum and ended up not being much explored by educators, in Brazil and the world. The idea behind such multidisciplinary approach in the school curriculum would be the discourse coherence of all teachers in the school environment and collective responsibility of the faculty that would facilitate to address various issues such as self-esteem, pubertal changes, respect sexual differences, prevention of diseases depending on each school achievement, and sexual initiation. All this in ordinary discourse and dialogue required for teacher training.

The present article will show the approach of sex education experience as a cross-cutting theme inserted in the annual planning of math teachers at the public schools of Florianopolis.

\section{Materials and Method}

\section{Students}

This is a cross-sectional and quantitative study performed through questionnaires administered to the students, before and after their participation in workshops on self-care and sexuality. The research subjects were students between 11 and 16 years old, from the fifth to ninth grades of municipal public schools that were previously selected.

The inclusion criteria were: 1) being a student regularly enrolled in the school grades involved and the schools participating in the project, and 2) wishing to fulfill the questionnaire. The exclusion criterion was the lack of signature by their parents or legal guardians of the free and informed consent term for the students fill out the questionnaires. The information was obtained through an anonymous and self-administered questionnaire given to the participants, in the school class period. The questionnaires were delivered to the students and collected by the elementary school teachers along with the medical students.

The analyzed variables were age, gender, school grade, if the student has children, if the student already had sexual activity, age of the first sexual intercourse, condom use frequency. It was also applied, with parental consent, questionnaires on prior knowledge about sexual diseases transmission, sexually transmitted infections known by the schoolchildren, methods of prevention of sexually transmitted diseases, and what were the most significant factors, in children's opinion, to decide when to start sex life. The questionnaires were completed before and after the workshops with parents' authorization. The questionnaires were entered and analyzed in the program Epi INnfo 7. It was considered a significance level of $5 \%$.

Schools

The schools were selected through technical criteria by the Coordination of 
the School Health Program (Government's Program: Programa Saúde na Escola) of the municipality that included the vulnerability of communities and demands required by the schools themselves.

\section{Workshops}

Initially, there was an identification of the information needs relating to the adolescents and a collection of specific local problems [19]. Since sexuality is a cross-cutting topic that can be approached by different ways, in many compulsory subjects of the school curriculum, the workshops directly related to it were conducted in Mathematics classes [20]. They aimed to address various issues such as contamination with STDs, prevention methods, and knowing life's main factors for sexual life beginning (complete workshops in the complementary material). All the activities were engaged and articulated with the teachers' annual planning. Two school principals agreed to hold workshops in the field of math classes. The pedagogical team responsible for the school unit always decided the teaching groups and years in which interventions took place.

Ethics

The project was approved by the Committee of Ethics in Research with $\mathrm{Hu}$ man Beings of UFSC, under the number 15017813.0.0000.0121 (with due amendments). The confidentiality about the information source was maintained. The questionnaires were only answered by the students who had informed consent document signed by their parents or legal guardians.

\section{Results and Discussion}

\section{Characterization of the students participating in the program}

The pedagogical workshops attended 1230 elementary school students from 15 public schools. All the students that participated of the project activities were invited to participate in the study, at all the participating schools; however, only those who brought the informed consent signed by their parents or legal guardians were able to complete the questionnaire. A total of 255 students answered the questionnaires, and all delivered questionnaires were considered for analysis.

The main characteristics of the group (students who responded to the questionnaires) are shown in Table 1 . The studied population is constituted predominantly by teenagers between 11 and 12 years, and enrolled between the fifth and ninth grades of the public elementary schools, in Florianopolis. It is one of the main changes the program has undergone in recent years, prioritizing workshops focused on fifth and sixth grades of the elementary school. The idea was to act preventively and face the anticipation of adolescents' sexual lives, which was a situation already evident in 2016 [5]. Sexual life onset among adolescents is mainly between 12 years or less (61.11\%; Table 2), and almost $14.8 \%$ of the total does not use or occasionally uses condoms (Table 3 ).

Comparing with a study published by the research group in 2016, it is worth considering the use of the condom (Table 4) as a crucial aspect that tends to reveal greater self-care of adolescents, and provoking the statistically significant 
Table 1. Characteristics of the students interviewed.

\begin{tabular}{ccc}
\hline Age & $\mathbf{n}$ & $\%$ \\
\hline 12 years or less & 147 & 57.7 \\
13 - 14 years & 92 & 36.0 \\
15 years or more & 16 & 6.3 \\
Ignored/no answer & 0 & 0 \\
Gender & & \\
Feminine & 139 & 54.5 \\
Masculine & 114 & 44.7 \\
Ignored/no answer & 2 & 0.8 \\
School grade & & \\
$5^{\circ}-6^{\circ}$ & 132 & 51.7 \\
$7^{\circ}, 8^{\text {a }}$ and $9^{\mathrm{a}}$ & 123 & 48.3 \\
Ignored/no answer & 0 & 0 \\
\hline
\end{tabular}

Table 2. Sexual life beginning in the adolescents of the program.

\begin{tabular}{cccc}
\hline & $\mathbf{n}$ & $\%$ & $\%$ \\
\hline First sexual intercourse age & & & \\
12 years or less & 33 & 12.95 & 61.11 \\
$13-14$ years & 18 & 7.05 & 33.33 \\
15 years or more & 3 & 1.17 & 5.56 \\
Did not start & 200 & 78.43 & \\
Ignored/no answer & 1 & 0.4 & \\
\hline
\end{tabular}

*54 students reported that already had sexual activity and they also responded about the age of their first sexual intercourse.

Table 3. Frequency of condom use in adolescents' sexual relationships.

\begin{tabular}{cccc}
\hline & $\mathbf{n}$ & $\%$ \\
\hline Use of condom ${ }^{*}$ & & \\
Always & 38 & 70.4 \\
Often & 8 & 14.8 \\
Ocassionally/Never & 8 & 14.8 \\
\hline
\end{tabular}

*54 students responded on the condom use.

Table 4. Comparison of advances in sexual health and education program.

\begin{tabular}{cccccc}
\hline & \multicolumn{2}{c}{$\begin{array}{c}\text { Use of condom (in 2016) } \\
(\mathrm{n}=67)\end{array}$} & \multicolumn{2}{c}{$\begin{array}{c}\text { Use of condom } \\
(\mathrm{n}=54)\end{array}$} & $P$ \\
\cline { 2 - 5 } & $\mathrm{n}$ & $\%$ & $\mathrm{n}$ & $\%$ & \\
\hline Always & 41 & 61.19 & 38 & 70.38 & 0.147 \\
Often & 6 & 8.96 & 8 & 14.81 & 0.158 \\
Ocassionally/Never & 20 & 29.85 & 8 & 14.81 & $0.025^{\star}$ \\
\hline
\end{tabular}

2016 data were published in the open journal of social science; ${ }^{\star} P<0.05$. 
decrease of $15.04 \%$ among adolescents who never used or have occasionally used condoms in their sexual relations [5]. It is significant to mention that the adolescents' behavior change to protect themselves coincided more clearly with our interventions' expansion by exploring non-classical program areas for sex education. Thus, the research group considers the use of math classes as one of the most relevant tools in the advances achieved by our program among adolescents, in the last years, and that is why we are going to detail these mathematics workshops below.

\section{The Inclusion of Sexual Health in Math Classes}

Mathematics Workshop: more than numbers, source of information, knowledge and prevention.

The school curriculum must be understood as a socialization process in order to make the children understand and consciously act, in the society [10]. In this sense, it is believed that the social relations, exchanges of experiences and daily life form a set of factors that guarantees and seeks to integrate the school life to the social life. Therefore, one wanted to integrate the curriculum of mathematics that provides from sixth to eighth grades of elementary education as knowledge objects: numbers and operations, algebra and information treatment. The studied contents, in the practice and during those years, in relation to the skills are percentage, data organization and collection, reading and interpreting charts, lists, diagrams, tables and graphs [21].

The skills and abilities to be developed by the students are: 1). Recognizing the importance of percentages in the scientific and social context. 2) Interpreting the data presented in the form of tables and graphs, and valuing that language as a communication form, and 3) Analyzing real situations [21]. Then, the guiding principles of the mathematics curriculum were clearly linked with the proposal for a workshop on sexual health education. That is because the school curriculum intends to build the meaning of measures used in the social context and other areas of knowledge by applying them on a daily basis.

Thereby, nothing better than bringing the Brazilian epidemiological bulletin data on STDs/HIV [1] (Workshop number one included in the complementary material) to discuss graphically and with tables the frightening reality of contamination of children and adults with HIV, in the studied municipality, and compare it with other regions of Brazil. Then, data presented in Table 5 reveal the background of previous knowledge of 12 out of 14 students of a sixth-grade class who affirm they do not know or do not respond to the forms of STD transmission. Conversely, the knowledge acquired in mathematics workshops in which 14 out of 14 students describe, at least, three types of contagion. Also, it was possible to provoke the students concerning forms of prevention against STDs in another math class. In Table 5 we can observe that 3 out of 14 students stated, in the previous knowledge evaluation, that condoms are a form of prevention in contrast to 12 out of 14 students who affirm knowing the condom as a 
Table 5. Evaluation of sex education workshops included in math classes.

\begin{tabular}{ccc}
\hline & $\begin{array}{c}\text { Pre-intervention } \\
\text { (prior knowledge/control) } \\
(\mathbf{n}=14)\end{array}$ & $\begin{array}{c}\text { Post-intervention } \\
(\mathbf{n}=14)\end{array}$ \\
\hline Transmission of DSTs & 1 & $11^{*}$ \\
Sexually & 1 & 3 \\
Skin cut & 0 & 2 \\
Do not care & 5 & 12 \\
Do not know & 7 & 1 \\
Ignored/no answer & & \\
Prevention & 3 & \\
Using condoms & & \\
Do not relate to anyone & & \\
Using pills & 1 & \\
Bgnored/no answer & 1 & \\
Do careful to see if the person has a cut & 4 & \\
No way to avoid & 5 & \\
Do not know & & \\
\hline
\end{tabular}

${ }^{*}$ Two children answered two different forms of transmission.

form of prevention, at the end of the interventions. Post-intervention assessments were always carried out at the end of the year, and usually, four months after the intervention.

In the practice, it was possible to transform a math class into the possibility of a broad discussion with teens about preventing from sexually transmitted diseases and educate the adolescents on the need for protection, care and respect for their own bodies, and also, their peers' ones. Therefore, our research group believes that preventive and self-care aspects can be developed in adolescents when approached in a cooperative and trusting environment, and we disagree that prevention is not taught [22]. Experiences and different views of other teens on a crucial subject may trigger necessary changes in the desire to protect themselves, leading to a belief that prevention can instead be cultivated by thinking of the teaching process as a collective experience, according to the research group experience.

Another critical and delicate aspect of the research work in schools is about parents' low adherence to the program and their majority refusal to authorize their children for the evaluation questionnaires' completion. The numbers in Table 5 (only 14 schoolchildren with signed consent terms out of 65 ) show the profound difficulties and limitations to making an objective and statistical evaluation of the research. Also, another recurring issue is the very late completion of the terms of free and informed consent, which made it difficult to assess the students' prior knowledge before workshops started. Thus, it was normal to start 
the year's activities without parental authorizations and without being able to know how much they know about specific topics. In practical terms, it was a contradiction because we used to prepare a workshop without knowing, most of the times, the target audience. Anyhow, the situation was avoided by assessing, at the end of the year, knowledge about STD transmission and prevention forms with other teaching groups of the same school year and similar age that did not participate in the program. It is worth emphasizing that only some teaching groups were benefited in the schools participating in the program. The pedagogical team of each school always selected the students' group and year that participated in the program based on their priorities and technical criteria.

Despite this hindrance due to the low number of signed consent terms, all schoolchildren prioritized by the pedagogical teams (1230 in total) participated in the workshops and effectively benefited from the program's work since the activities were part of the educational planning. One of the advantages of engaging such planning activity is that parents cannot prevent their children from attending workshops. Parents, from the research group point of view, believe that their children's participation in a sex education program will end up encouraging them to start their sex lives. Literature data show that sex education programs engaged at the school end up effectively delaying sexual life onset [6] [23] [24].

Workshop on Mathematics. Equational Reasoning in Everyday Life

Mathematics is known as a discipline that often brings difficulties to teenagers. A demonstration of this is the low performance in the subject verified by the SAEB (Brazilian Education and Evaluation System) with an oscillation in the means of proficiency in mathematics and decrease in the last six years, in all regions of Brazil. There was growth resumption only in the last two years, in the North and Northeast of Brazil [25]. Does such difficulty happen because the students do not glimpse the practical use of mathematics? It is an old dilemma. What is better? Knowing pure mathematical science or practical mathematics that applies to everyday problems. It is worth saying that mathematical knowledge gains meaning when students have challenging situations to solve and work collectively to develop strategies for resolution.

Therefore, following the guiding principles of mathematics curriculum [21], we set the challenge of analyzing all possible components that lead a teenager to decide when and how the sex life starts. The goal is to include these factors as variables of an equation and assign a value that each component or variable will have in the final result of this significant equation on the everyday life of any teenager: When am I ready to start sex life? In this workshop, it was possible to imagine that each equation could be different and each equation component could have a different value and meaning for every child participating in the workshop (workshop two is in the supplementary material). The idea is the production of a substantially different mathematical knowledge that follows profound aspects of the educational process. 1) Understanding how different the 
personal processes are and 2) it is more significant to teach/ learn to respect such differences that lead persons through different ways to the same equation resolution on when starting the sex life.

Then, what are teachers going to teach in equational reasoning classes? According to the authors, the basis of a solid sexual education is to respect the differences. Respect, in sex education, is the citizenship building basis and healthy sexuality beginning. Learning all together to value the different dimensions of such significant decision (sexual initiation), visualizing different ways of interpreting sexuality, and perhaps, mirroring and recontextualizing people's views with another teenager's equation are permanent challenges in the program's construction. Paulo Freire's profound reflections considering the teaching process as a co-participatory one in which everyone learns with everyone are inserted appropriately in the present proposal context [26].

Therefore, it is expected an understanding of multiple aspects that dimension the sexual initiation, some of them incredibly complex, and where cultural differences of race and religion should permeate the discussion on sexual life equational reasoning. Maybe, it is possible to give up the biomedical aspect of sex education, and one's come to appreciate a cultural and social vision of education. Also, it will contribute to breaking the paradox of incomprehensible math, a matter so present and essential on people's daily lives that few people may appreciate. The current workshop has not been evaluated in the research group's program, yet.

\section{Final Considerations}

The aim of promoting sexual health and respect for differences such as sex education components, in general, is satisfactory through workshops engaged in school planning. However, it is worth recognizing that these are pilot projects with an insufficient scope if they are not inserted in broader political action. The idea is to reveal that it is possible, in practice, to develop sexual education in the school context and mathematics teaching by following the guidelines of the national curricular parameters [10]. Nevertheless, it is worth mentioning that sexual education insertion or health promotion actions, in the school curriculum, will not be practical unless all institutions assume co-responsibilities regarding the insufficient response to sexual education needs of the Brazilian adolescents. [27]. It is possible to say that a correct inter-institutional relationship should be established among universities, schools (ministry of education), health centers (ministry of health), and along with governments of any sphere should help to develop sex education, in the school curriculum, as a state policy.

Thus, by bringing the reality of the students to the classroom and relating it to the subjects' content (such as mathematics or any other discipline, for example), it is possible to obtain the students' participation and involvement to build the knowledge, organization and development of their skills and abilities, in their multiple dimensions [28]. It is possible to change the student's role in the class- 
room, by changing practices. It is possible to change the teacher's role in the classroom by changing practices, and then, it is possible to strengthen the possibility of turning the actions on health promotion into pedagogical and educational actions with real meaning for the school environment.

Thus, our article's most significant issue was to reveal and experience, at the same time, that mathematics is present in all aspects of a teenager's daily life. Also, its use in the prevention of STDs and promotion of self-care behaviors turns math into the most interesting school subjects to explore in the approach of pedagogical strategies in sexual health for children between 11 and 15 years old.

Finally, it is significant to highlight the school teams' support and commitment, and fundamentally, the mathematics teachers' role to contribute to the maintenance of the program for so many years. The teachers have transformed their classes to promote health. They have become real health agents, faithfully fulfilling their role as creative educators and committed to the Brazilian population's health and education.

\section{Acknowledgements}

We wish to thank the ex-Coordinator of the School Health Program, Giorgia Wiggers; the ex-Ongoing Training Manager of the Municipal Secretary of Education, Gisele Pereira Jacques; the Principals and Teachers of the Primary Municipal Schools: Mâncio Costa, Osvaldo Machado, João Gonçalves Pinheiro, Henrique Veras, Donícia Maria da Costa, João Alfredo Rohr, Maria Conceição Nunes, Maria Tomázia Coelho, that contributed to the success of the program. This Program was supported by Ministry of Education, MEC Sesu Proext-2013 and Proext-2014, Pro-Bolsas-UFSC 2015, 2016 e 2018.

\section{Competing Interests}

The authors declare that they have no competing interests.

\section{References}

[1] Brazil Boletim Epidemiológico DSTs/AIDS. Ministerio da Saúde, Brasilia, DF, 2017.

[2] Currie, C.N.G.S., Roberts, C., et al. (2012) Social Determinants of Health and Well-Being among Young People. Health Behavior in School-Aged Children (HBSC) Study. International Report from the 2009/2010 Survey. WHO Regional Office for Europe, Copenhagen.

[3] Brazil Pesquisa Nacional de Saúde do Escolar (PENSE) (2015) Instituto Brasileiro de Geografia e Estatística, Ministerio da Saúde, Rio de Janeiro.

[4] Malta, D.C., Silva, M.A.I., et al. (2011) Sexual Health of Adolescents According to the National Survey of School Health. Revista Brasileira de Epidemiologia, 14, 147-156.

[5] Ues, B., de P.G. Moreira, A.V., et al. (2016) The Public University in Brazil Is Revisiting Its Social Commitment to Establish a School-Based Sex Education Program. Open Journal of Social Sciences, 4, 124-139. https://doi.org/10.4236/jss.2016.49012 
[6] Ma, Z.Q., Fisher, M.A., et al. (2014) School-Based HIV/AIDS Education Is Associated with Reduced Risky Sexual Behaviors and Better Grades with Gender and Race/Ethnicity Differences. Health Education Research, 29, 330-339. https://doi.org/10.1093/her/cyt110

[7] Pirotta, K.C.M., Barboza, R., et al. (2015) Sexual Orientation Programs in Schools: an Analysis of Gaps in the Implementation of the Public Policies Based on the Students' Perception of the City of São Paulo. Revista Gestão \& Políticas Públicas, 3.

[8] IPPF/RHO Barômetro latino-americano sobre o acesso das mulheres aos contraceptivos modernos. Federação Internacional de Planejamento Familiar, 2015.

[9] Andrade, H.H.S.M., de Mello, M.B., et al. (2009) Changes in Sexual Behavior Following a Sex Education Program in Brazilian Public Schools. Cadernos de Saúde Pública, 25, 1168-1176. https://doi.org/10.1590/S0102-311X2009000500023

[10] Brazil Parâmetros Curriculares Nacionais (1998) Terceiro e quarto ciclos: Apresentação dos temas transversais.

[11] Vieira, P.M. and Matsukura, T.S. (2017) Frameworks of Sexual Education: Cconceptions and Practices of Public Middle School Teachers. Revista Brasileira de Educação, 22, 453-474. https://doi.org/10.1590/s1413-24782017226923

[12] da Silva, D.R.Q. (2014) Sex Education in the Eyes of Brazilian Public School Teachers. Creative Education, 5, 1418-1427. https://doi.org/10.4236/ce.2014.515160

[13] da Silva, D.R.Q., Guerra, O.U., et al. (2013) Sex Education in the Eyes of Primary School Teachers in Novo Hamburgo, Rio Grande do Sul, Brazil. Reproductive Health Matters, 21, 114-23. https://doi.org/10.1016/S0968-8080(13)41692-0

[14] Treichler, P.A. (1987) AIDS, Homophobia, and Biomedical Discourse: An Epidemic of Signification. AIDS: Cultural Analysis/Cultural Activism, 43, 31-70.

[15] Parker, R.G. and Aggleton, P. (1999) Culture, Society and Sexuality: A Reader. Taylor \& Francis, London. https://doi.org/10.4324/9780203212998

[16] Furlani, J. (2011) Educação sexual na sala de aula: Relações de gênero, orientação sexual e igualdade étnico-racial numa proposta de respeito às diferenças. Autêntica, Belo Horizonte.

[17] Furlani, J. (2009) Encarar o desafio da educação sexual na escola. In: Sexualidade, SEED, Curitiba, 37-49.

[18] Darido, S.C., Rangel-Betti, I.C., et al. (2017) A educação física, a formação do cidadão e os parâmetros curriculares nacionais. Revista Paulista de Educação Física, 15, 17-32. https://doi.org/10.11606/issn.2594-5904.rpef.2001.139482

[19] Aggleton, P. (1992) Young People, HIV/AIDS and Social Research. AIDS Care, 4, 243-244. https://doi.org/10.1080/09540129208253096

[20] Cofre, J., Knobel, R., et al. (2014) School-Based Sex Education Program: A Multidisciplinary Experience Induced by Medicine Students. 3rd International Congress Sexuality and Sexual Education, Lisbon, 10-12 July 2014.

[21] (2011) Florianópolis Matriz Curricular do Ensino Fundamental de 9 Anos em construção. Prefeitura Municipal de Florianópolis. Secretaria Municipal de Educação. Diretoria de Ensino Fundamental.

[22] Ayres, J.R.C.M. (2002) Educational Practices and the Prevention of HIV/Aids: Lessons Learned and Current Challenges. Interface-Comunicação, Saúde, Educação, 6, 11-24. https://doi.org/10.1590/S1414-32832002000200002

[23] Tortolero, S.R., Markham, C.M., et al. (2010) It's Your Game: Keep It Real: Delaying Sexual Behavior with an Effective Middle School Program. Journal of Adolescent Health, 46, 169-179. https://doi.org/10.1016/j.jadohealth.2009.06.008 
[24] Vivancos, R., Abubakar, I., et al. (2013) School-Based Sex Education Is Associated with Reduced Risky Sexual Behaviour and Sexually Transmitted Infections in Young Adults. Public Health, 127, 53-57. https://doi.org/10.1016/j.puhe.2012.09.016

[25] INEP/MEC (2018) Relatório Nacional SAEB 2005-2015. Ministério de Educação, Brasília.

[26] Freire, P. (1996) Pedagogia da autonomia: Saberes necessários à prática educativa.

[27] Oliveira-Campos, M., Giatti, L., et al. (2013) Contextual Factors Associated with Sexual Behavior among Brazilian Adolescents. Annals of Epidemiology, 23, 629-635. https://doi.org/10.1016/j.annepidem.2013.03.009

[28] Kraft, J.M., Kulkarni, A., et al. (2012) Sex Education and Adolescent Sexual Behavior: Do Community Characteristics Matter? Contraception, 86, 276-280. https://doi.org/10.1016/j.contraception.2012.01.004 


\section{Mathematics Workshop 1}

Mathematics: more than numbers, source of information, knowledge and prevention.

\section{Introduction}

Information access is an essential step in building knowledge. Therefore, a challenge arises to know and control what is offered to these adolescents, and what is consumed by them on the Internet has become a complicated task for those responsible. It is a fact that access to available data on the network is facilitated. However, are these same individuals, who are inundated with information day by day, prepared to deal with what lies behind these numbers? In response to this demand, it was noticed the urgency to teach how to deepen the analysis of demonstrations (tables, graphs, etc.), applied in the social context of this age group students to empower and make them active agents of social change.

Thus, the Curricular Matrix of Basic Education of nine years provides the teaching of data collection and organization, interpretation and reading of tables, lists, diagrams, charts and graphs (bars, columns, sectors) for the sixth year. The aim was to develop skills and abilities to interpret the presented data and valuing such language as a form of communication. Then, it was proposed the application of this workshop, whose data leads them to think about a very pertinent theme to their social context: AIDS. It is a disease that for a long time has been characterized by reaching young gay men and/or drug users; however, it currently presents as a non-selective disease that has plagued the most diverse social groups. Presenting data that evidence this new perspective on AIDS and raising questions about this dissemination will show that mathematics, much more than free numbers, consolidates itself as the basis for an excellent critical reflection.

\section{Objective}

Presenting data with a history of HIV contamination showing the reality of AIDS in the present time, and focusing on Florianópolis. Based on these data presented in tables, lists, and graphs, which should be read and interpreted by the students, to discuss what has been a risk factor for contamination in the present day to make them think of prejudices, attitudes and, fundamentally, prevention methods.

\section{Strategy}

According to the National Teaching Plan, everyday topics such as sexuality should be approached in a cross-sectional way, in the classroom. Thus, when planning the lesson on reading and interpreting graphs, the math teacher will advocate the presence of different charts on AIDS, encouraging the students to realize how much the reality of the disease has changed in recent years.

Conducting the discussion based on their prejudice about the disease and showing through data that AIDS is no longer a disease of a group or gender, but 
J. Core et al.

instead, everyone should have due care and focus on transmission prevention.

4. Materials Needed

Data show

A computer for projecting tables and graphs

Data are available in http://svs.aids.gov.br/aids/

Incidência de Cuds em SC

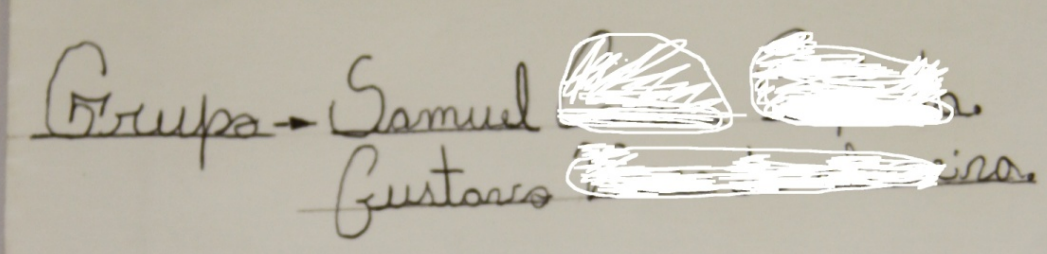

TUI MA $\rightarrow$ - 61

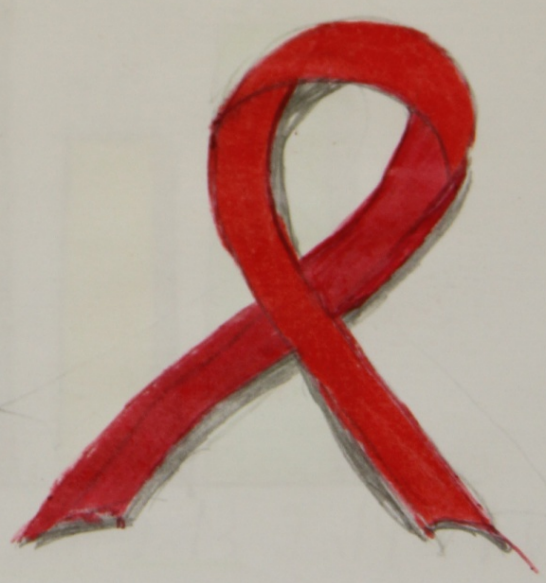

The picture was manipulated to preserve the identity of the children

DOl: $10.4236 /$ jss.2018.67016

217

Open Journal of Social Sciences 


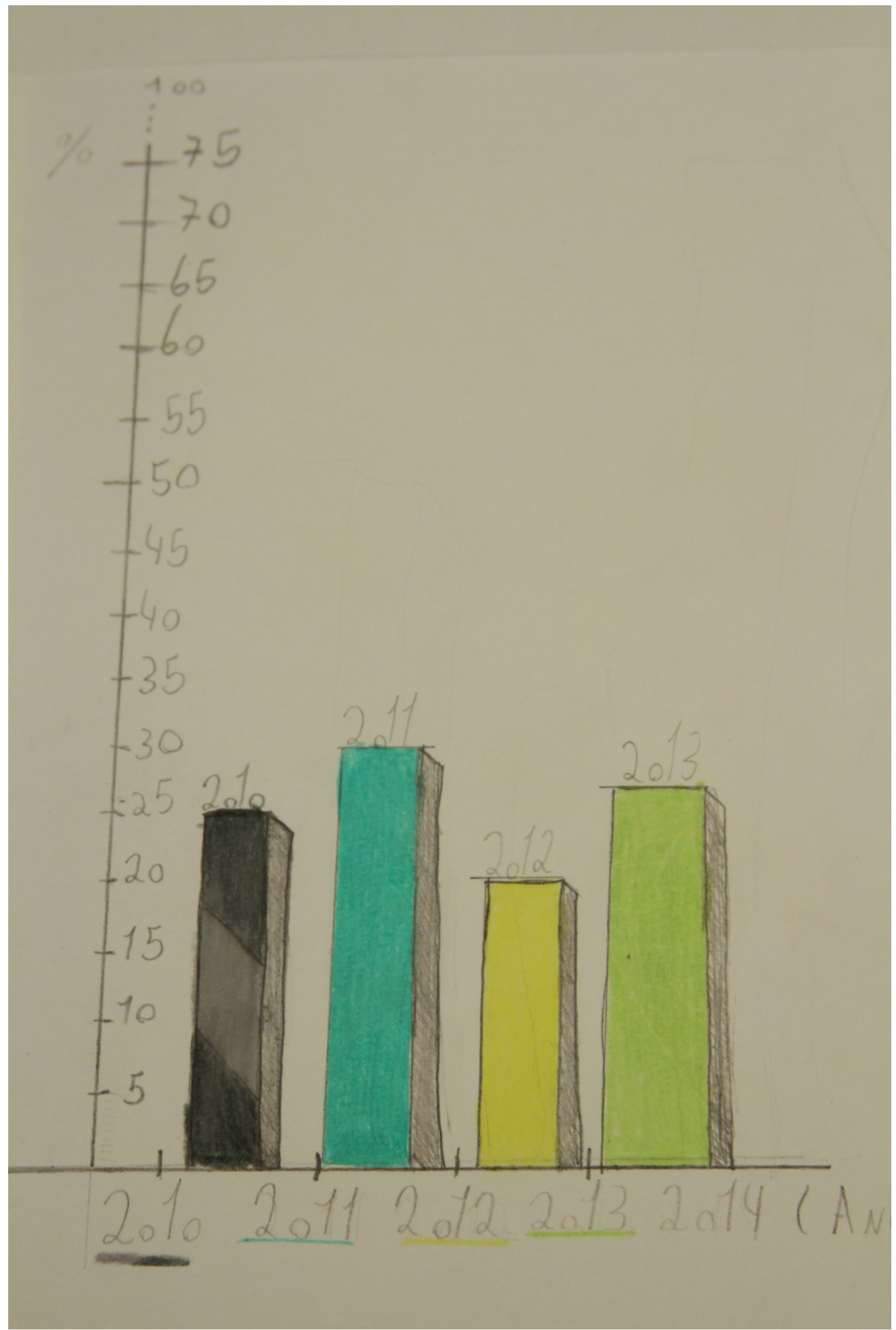




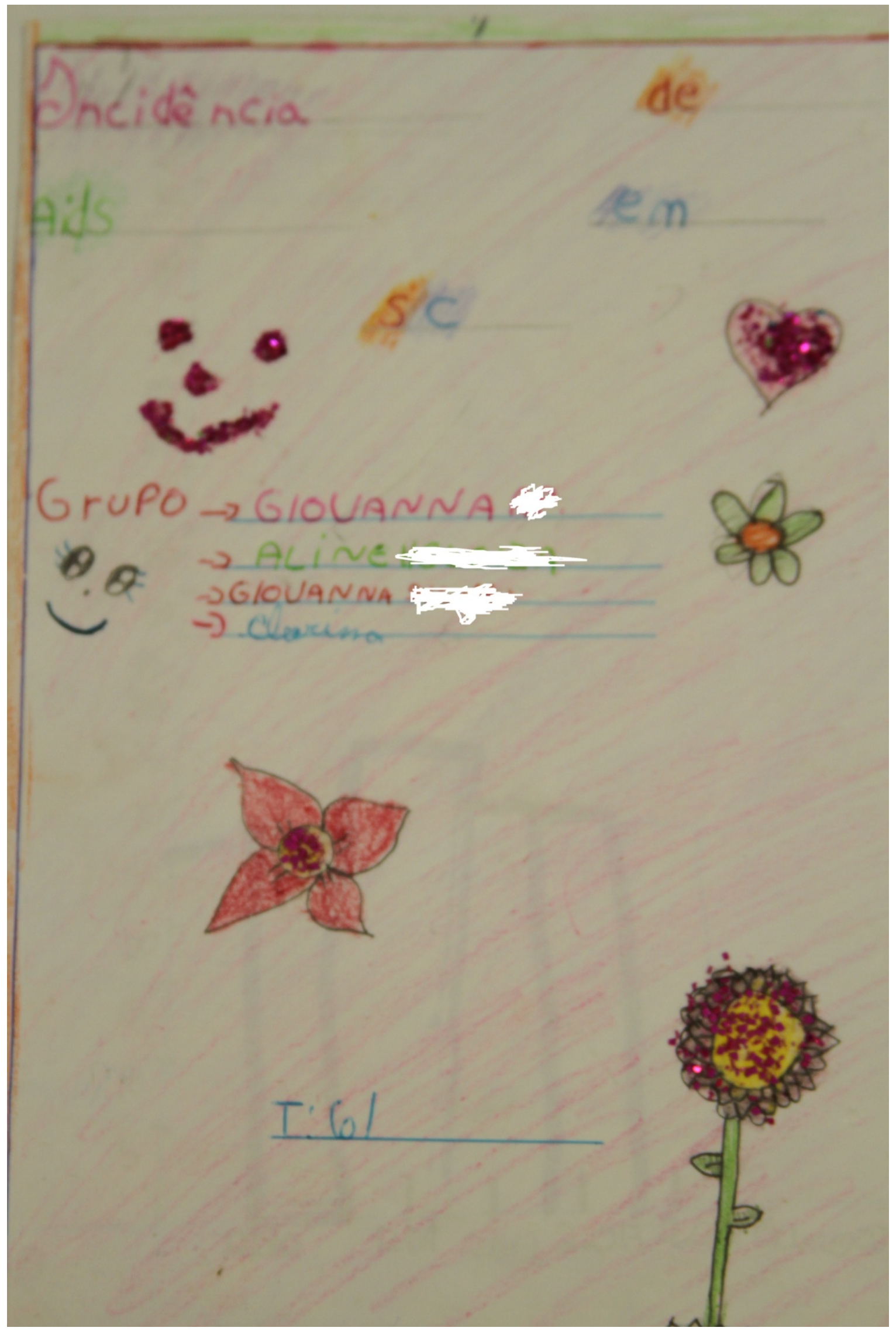


J. Core et al.

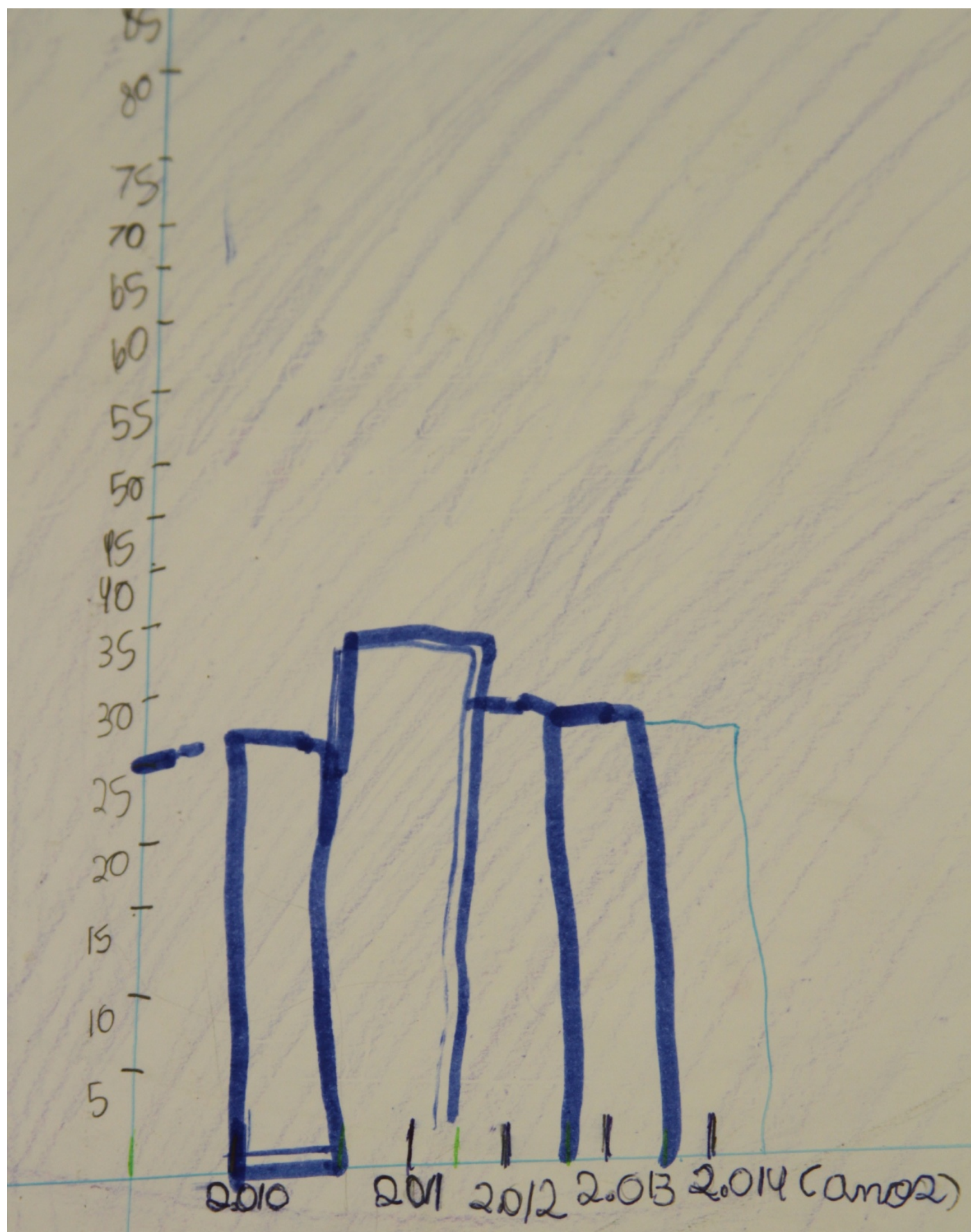

DOI: 10.4236/jss.2018.67016

220

Open Journal of Social Sciences 
J. Cofre et al.

Incidencia de Aids em Santa Catarina

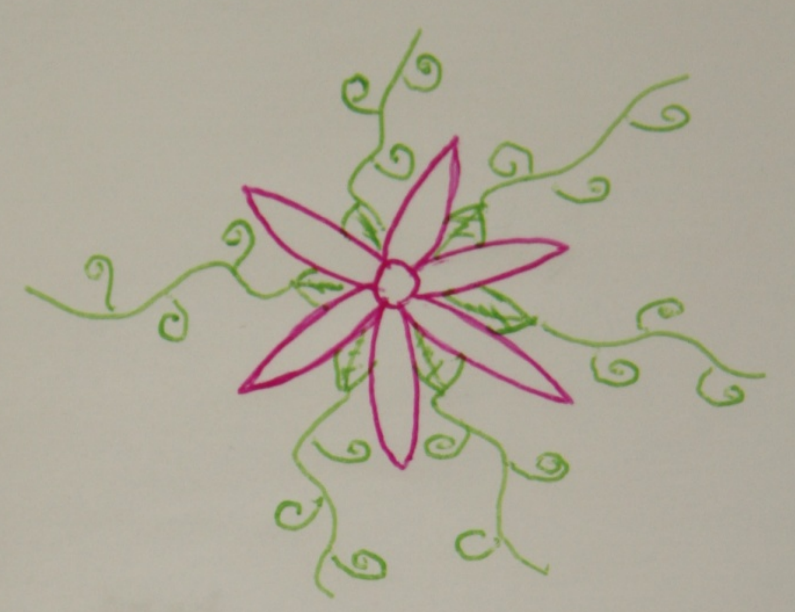

GRUPO:

Juliana. C

Manuela.R

Maria. C

Toisa.R

DOI: 10.4236/jss.2018.67016

221

Open Journal of Social Sciences 


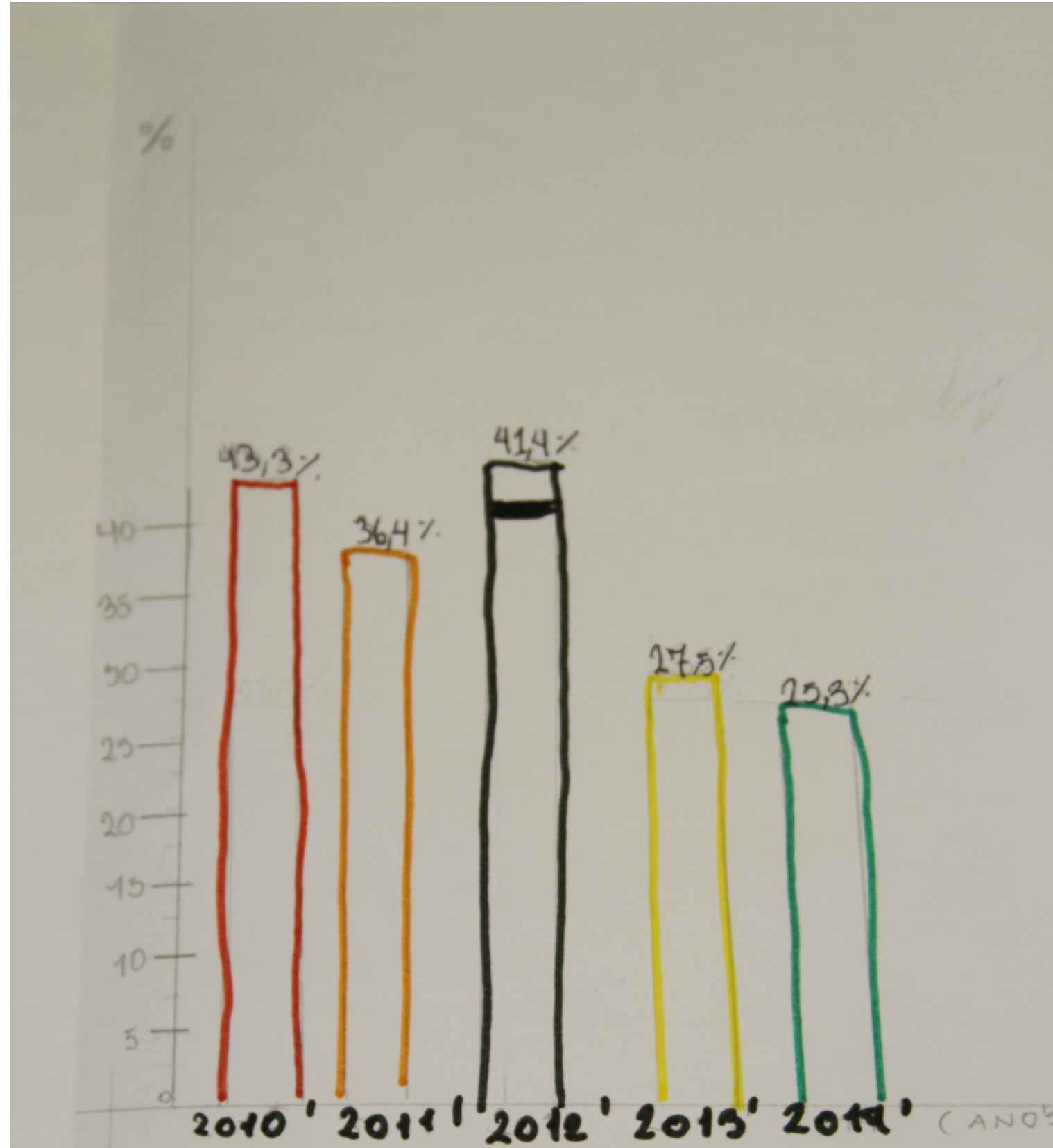



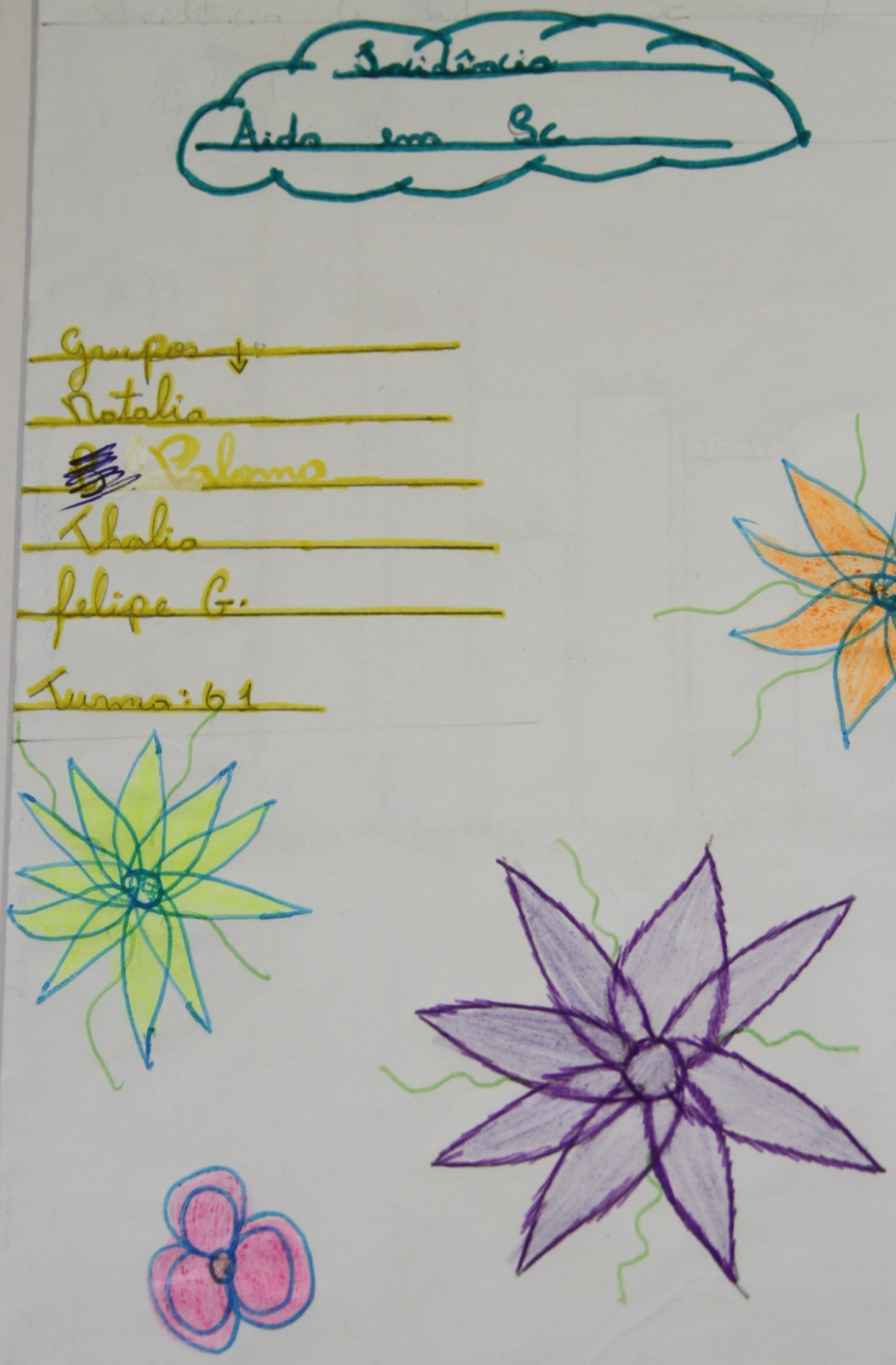


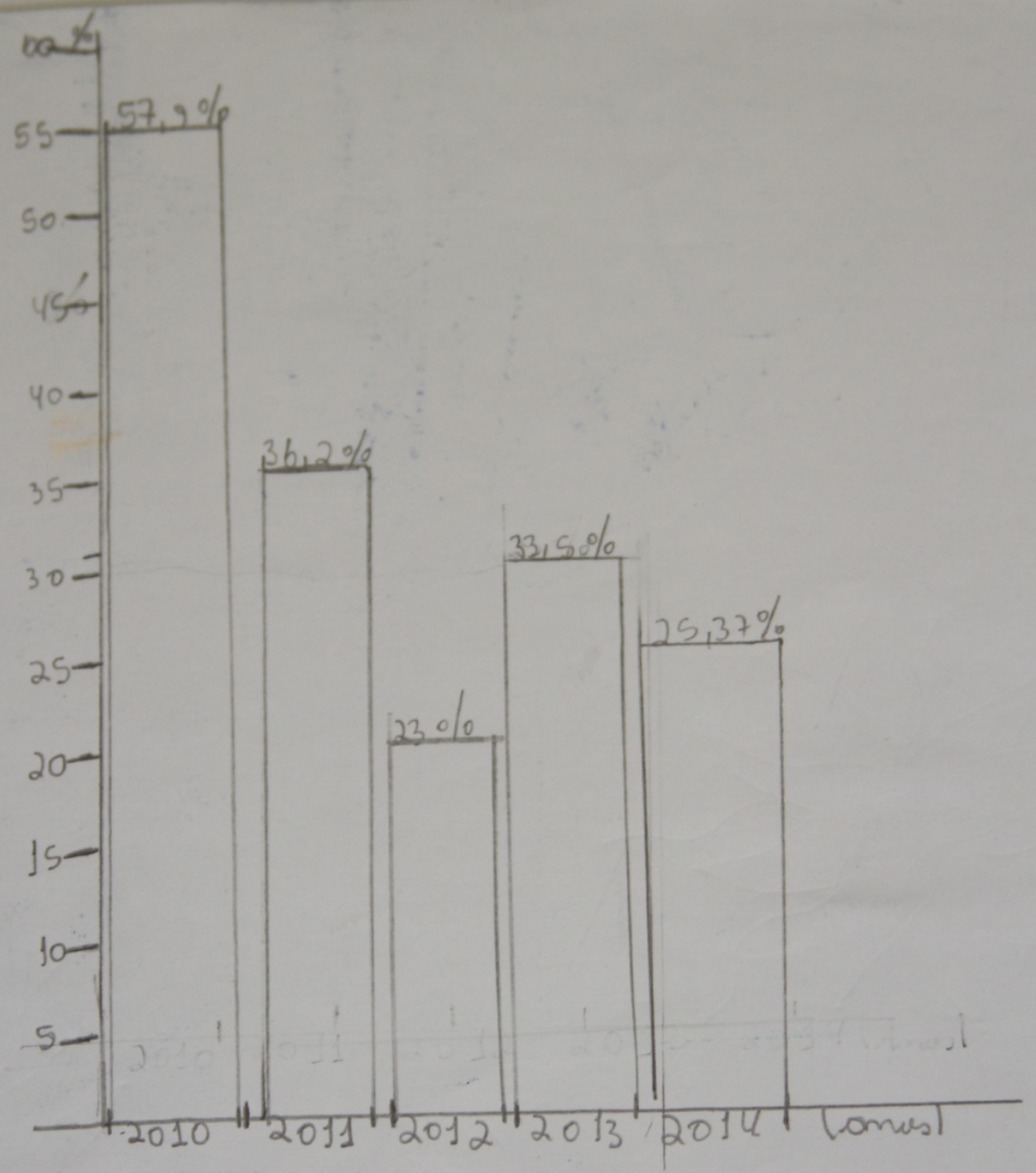


J. Core et al.

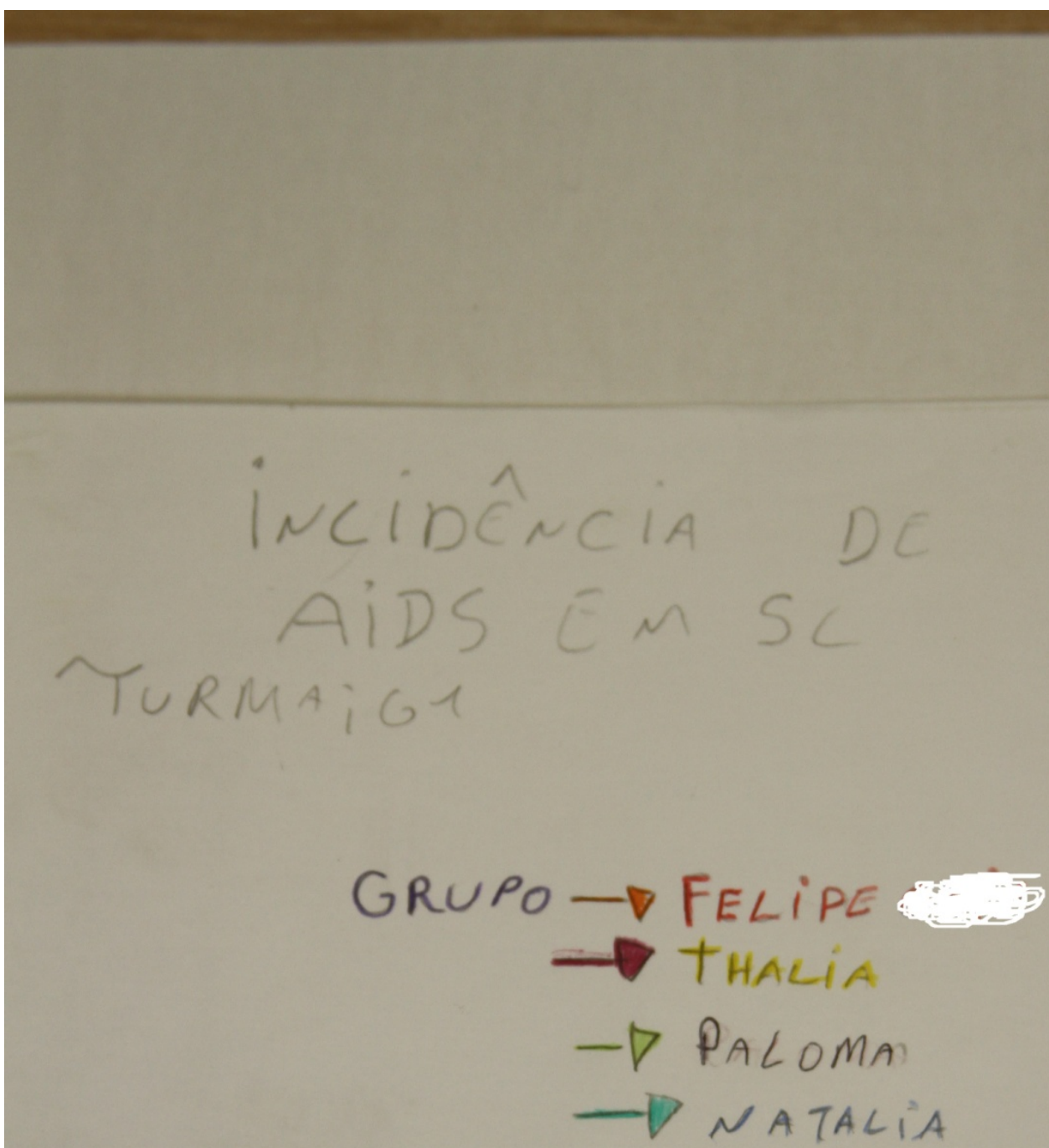

DOI: 10.4236/jss.2018.67016

225

Open Journal of Social Sciences 
J. Core et al.

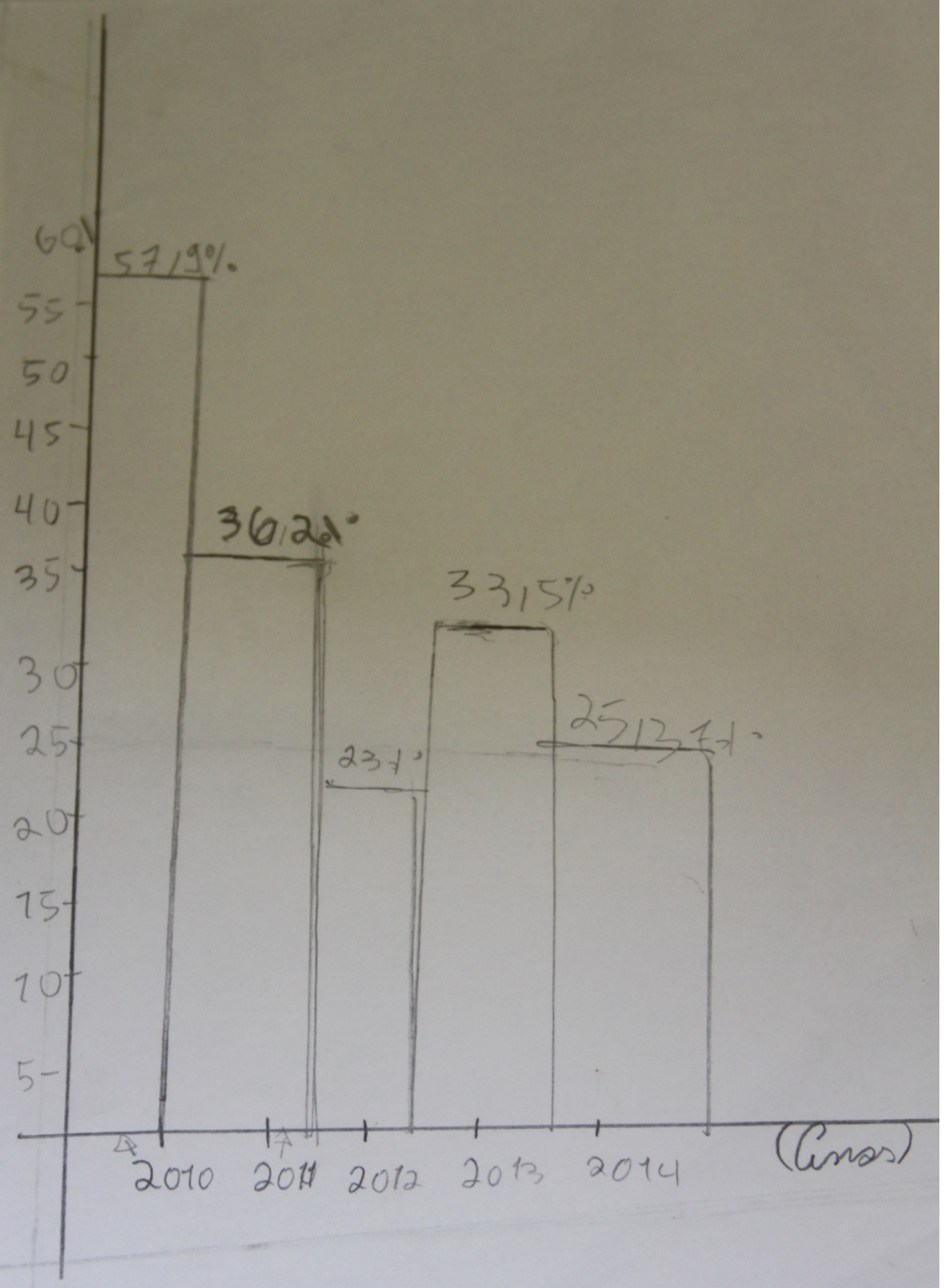

DOI: 10.4236/jss.2018.67016

226

Open Journal of Social Sciences 


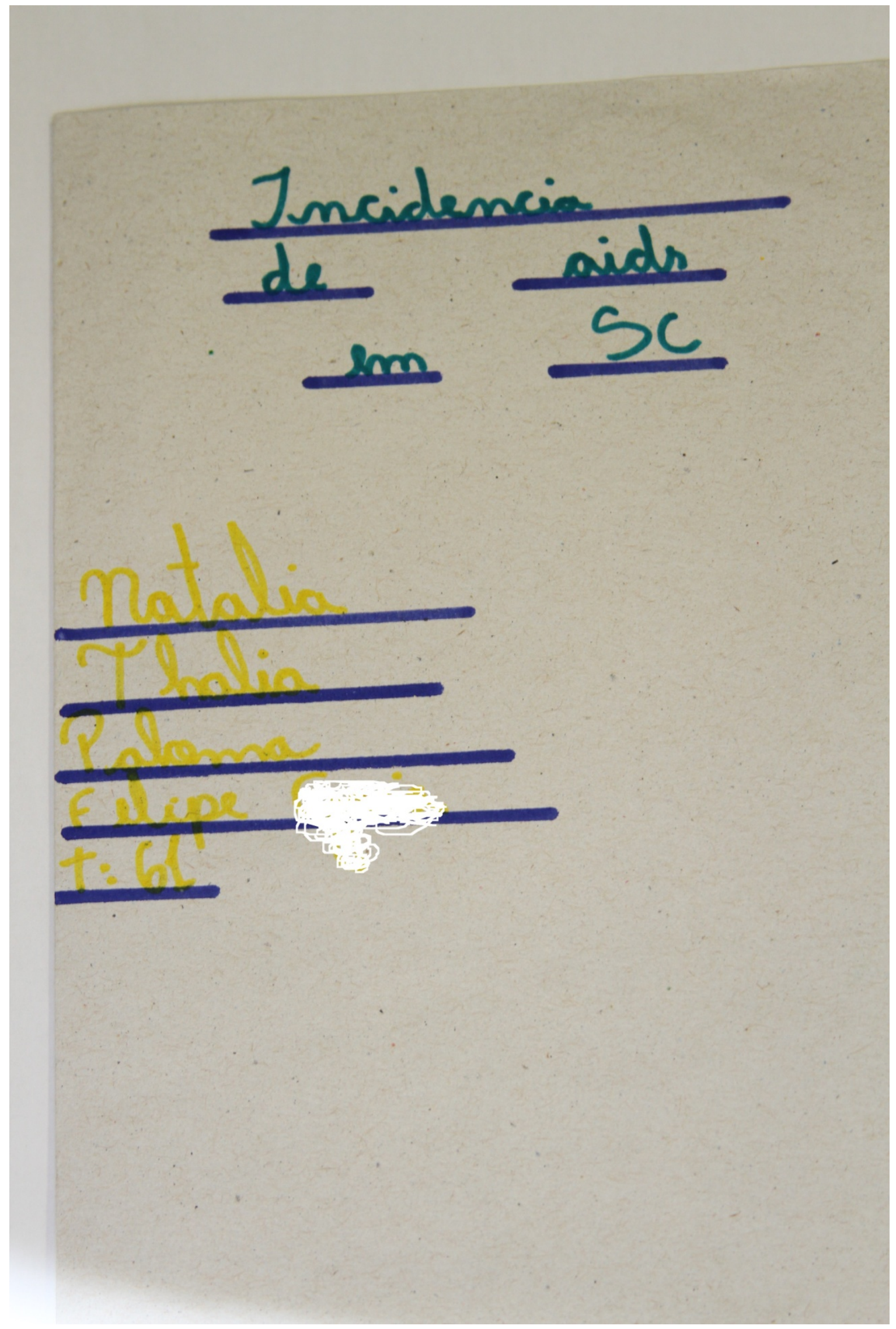




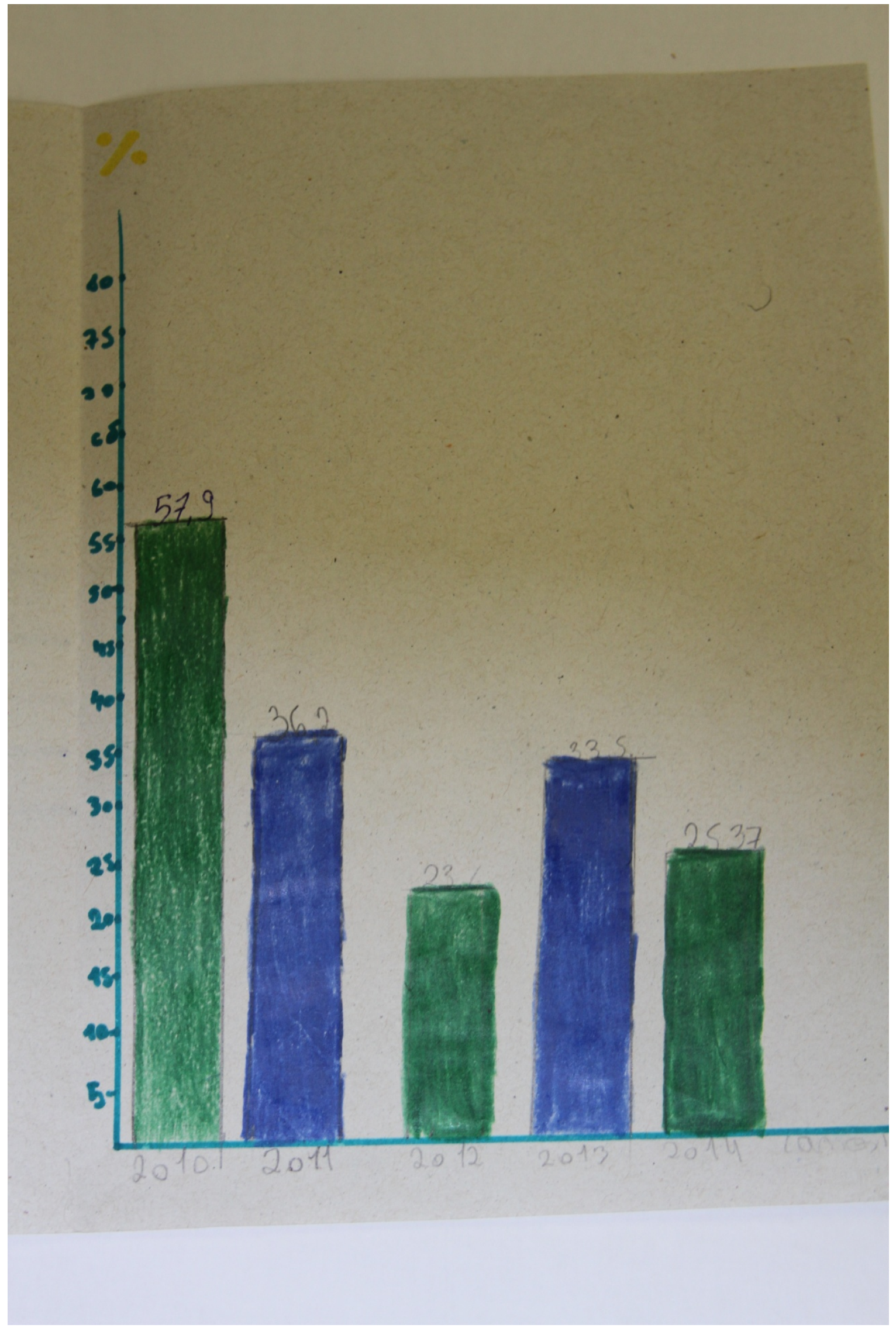




\section{Mathematics Workshop 2}

Equational reasoning in everyday life

\section{Introduction}

Adolescence is a phase of many changes in the life of any individual. It is a period of biological, psychological, and behavioral changes. It arises the need to make decisions that can determine people's lives in the midst of such whirlwind of news. A decision at this stage regards the teenager's sexuality. Lack of dialogue, information, and embarrassment are complicating aspects for an adequately reflected and successful choice.

In this context, the school appears as a fundamental agent of adolescent support and training with its various disciplines and commitment. Therefore, it is urgent the use of a cross-cutting approach to everyday topics within the classroom. It is challenging to use mathematics, for example, with subjects such as sexuality. However, working on mathematics applicability may promote greater acceptance and, consequently, increase the students' performance in the subject.

Thus, it is not perceived that, for example, when balancing pros and cons seeking solutions to problems or listing factors that lead to a result, the equational reasoning is inserted in each of these situations, proving that there is no way to separate mathematics from everyday life.

Then, the Curricular Matrix of Elementary Education of nine years provides for the 7th year the teaching of first grade equations, aiming to develop skills and abilities as the use of such properties to build strategies of algebra. Also, to represent and analyze real situations, it is suggested the insertion of this workshop that besides addressing concepts previously worked by the mathematics teacher, within the equations class, will provide more information about sexuality in adolescence to make these adolescents more capable of making necessary decisions.

\section{Objective}

Using concepts addressed in mathematics classes on first degree equations to stimulate the emergence of several reflections about multiple factors involved in the choices regarding sexuality in adolescence.

\section{Strategy}

The workshop is divided into three meetings. The strategy consists of presenting a central concept of discussion that could be the result of an equation (one side of equality). Then, the students should reflect and discuss, with the help of the workshop supervisor, the factors that should compose the equation and its due weights within it, so that perfect equality is achieved for them.

Themes proposals for the meetings:

- Encounter $1-$ Sexuality ( $\neq$ sex)

- Encounter 2-Healthy affective relationship 
- Encounter 3-Decide to start sex life

\section{Materials Needed}

Classroom structure (board and chalk). 